\title{
Patients with Alzheimer's disease and dementia with Lewy bodies mistaken for Creutzfeldt-Jakob disease
}

H J Tschampa, M Neumann, I Zerr, K Henkel, A Schröter, W J Schulz-Schaeffer, B J Steinhoff, H A Kretzschmar, S Poser

\begin{abstract}
Objectives-To describe the clinical presentation of patients with Alzheimer's disease (AD) or dementia with Lewy bodies (DLB) who were suspected of having Creutzfeldt-Jakob disease (CJD) and to investigate whether current clinical diagnostic criteria cover these atypical forms of AD and DLB.

Methods-Brains from necropsy were examined for the diagnosis of CJD at the German reference centre for spongiform encephalopathies. Symptoms and signs in patients with suspected CJD in whom necropsy showed AD $(n=19)$ or DLB $(n=12)$ were analysed. Their data were compared with a group of patients with CJD $(n=25)$ to determine overlapping and discriminating clinical features. All patients were classified according to clinical diagnostic criteria for CJD, AD, and DLB. Results-Demented patients were suspected of having CJD if disease was rapidly progressing and/or focal neurological signs appeared and/or an EEG showed sharp wave complexes. Myoclonus and limb rigidity were the most common neurological signs in all three dementias. DLB was not suspected in any patient, although patients with DLB showed parkinsonism (58\%) and fluctuations (58\%). Periodic sharp wave complexes (PSWCs) in EEG typical of CJD were found in five patients with $A D$ and one patient with DLB. 14-3-3 Protein in CSF was detected in 20 patients with CJD, in two patients with $A D$, but not in any patient with DLB. Although most patients with DLB or AD met the clinical criteria for their respective diagnosis $(74 \%$ and $90 \%)$, they also fulfilled criteria for CJD (42\% and $58 \%$ ). Conclusions-In patients with rapidly progressive dementia and focal neurological signs, CJD should be the first line diagnosis. Facing the triad dementia, myoclonus, and rigidity, AD should be considered if the disease course is longer and DLB is the differential diagnosis if parkinsonism or fluctuations are present. Findings on EEG or CSF typical of CJD do not exclude AD or DLB.

(F Neurol Neurosurg Psychiatry 2001;71:33-39)
\end{abstract}

Keywords: Creutzfeldt-Jakob disease; dementia with Lewy bodies; Alzheimer's disease; diagnosis
Creutzfeldt-Jakob disease (CJD), Alzheimer's disease (AD), and dementia with Lewy bodies (DLB) are human neurodegenerative disorders presenting with dementia as their principal sign. All three are of unknown origin and have a fatal outcome. Whereas CJD is a rare disease with an incidence of around one case/million/ year ${ }^{1} \mathrm{AD}$ and DLB bodies are the two most common causes of dementia in elderly people. ${ }^{2}$

In most cases, patients with CJD have a rapidly progressive disease course and periodic sharp wave complexes (PSWCs) in the EEG. They usually develop neurological signs such as gait disturbances or myoclonus. Most patients become bedridden and die after a median disease duration of 7 months. ${ }^{1}$ Generally, $\mathrm{AD}$ is of slow course (duration of illness 7-8 years ${ }^{3}$ ) and neurological signs appear only in late stages of the disease. ${ }^{4}$ DLB was recently defined as a separate disease entity with the characteristics of dementia, parkinsonism, visual hallucinations, fluctuations in cognitive impairment, and neuroleptic hypersensitivity. ${ }^{5}$ Life expectancy in DLB of 5-8 years is shorter than in $\mathrm{AD}^{25}$

Studies on patients with DLB whose diagnoses were confirmed by necropsy focus on the clinical differentiation of DLB and $\mathrm{AD}^{67}$ or DLB and Parkinson's disease. ${ }^{89}$ They have included only a few patients. There are case reports of necropsy confirmed patients with $\mathrm{AD}^{10-12}$ and patients with $\mathrm{DLB}^{13}$ in whom CJD had been clinically suspected, but no systematic study has yet been undertaken to differentiate those patients with a rapidly progressive disease course.

In our study we describe a larger number of patients suspected clinically of having CJD but in whom $\mathrm{AD}$ or DLB was shown at postmortem examination. Frequency of clinical signs and symptoms and the results of technical investigations are reported. Reliability of current clinical diagnostic criteria for CJD, DLB, and $A D$ is evaluated, and a diagnostic pattern is proposed to facilitate clinical differential diagnosis.

\section{Materials and methods}

PATIENTS

Since 1993 brains from necropsies have been sent to the German reference centre for spongiform encephalopathies for the diagnosis of Creutzfeldt-Jakob disease or genetic prion disease. Most patients necropsied were examined as suspected CJD cases during their lifetime by a study physician of the German CJD surveillance unit. 
We collected clinical data from patients in whom CJD was ruled out by neuropathology, and in whom AD or DLB were confirmed.

The control group of 25 patients with definite sporadic CJD was recruited from patients consecutively referred to the CJD surveillance unit in the same period as the patients with $\mathrm{AD}$ and those with DLB. Recruitment of patients with CJD ceased as soon as a representative group of patients was achieved that corresponded in clinical signs and symptoms to our previous findings. ${ }^{1}$ Patients with genetic $^{14}$ or iatrogenic prion disease were excluded.

ANALYSIS OF CLINICAL DATA

Medical records of all patients were studied retrospectively. Each patient's chart was analysed with a standardised checklist, which contained the following items:

(1) Reason for sending in material for prion disease analysis.

(2) Signs and symptoms typical for CJD were rated according to modified Masters criteria. ${ }^{15-17}$ Extrapyramidal signs were subdivided into limb rigidity, parkinsonism, and dystonic, choreatic, athetoid or ballistic movements. Visual disturbances included deteriorated or blurred vision, visual field restriction, and disturbed perception of structures and colours. Visual hallucinations were rated separately.

Clinical features of $\mathrm{AD}$ were rated according to NINCDS-ADRDA criteria. ${ }^{4}$

Clinical features of DLB were noted according to McKeith et al. ${ }^{5} 18$

(3) Technical investigations: All EEGs were initially reviewed by one of us (SP). The EEGs were additionally reviewed without knowledge of clinical information by a second observer (BJS). ${ }^{19} 20$ "CJD typical EEG" was diagnosed in EEG tracings fulfilling Steinhoff's criteria. Testing for protein 14-3-3 and neuron specific enolase (NSE) in CSF was performed as previously described. ${ }^{16} \mathrm{~A}$ cut off for CJD was defined as NSE concentration $>35 \mathrm{ng} / \mathrm{ml}$ in $\mathrm{CSF}^{16}$

CLINICAL CLASSIFICATION OF PATIENTS

Using the results from the above checklist, patients were classified according to international diagnostic criteria for CJD, ${ }^{15}{ }^{16} \mathrm{AD},{ }^{4}$ and DLB. ${ }^{5}$ Each patient was clinically classified for all three dementia entities. The categories "possible", "probable", and "other disease" (not fulfilling the criteria) were used to express the degree of certainty in the clinical diagnosis.

NEUROPATHOLOGICAL EVALUATION

Brains were fixed in $10 \%$ formalin for at least 14 days. Representative blocks were cut, decontaminated for 1 hour in concentrated formic acid, ${ }^{21}$ and embedded in paraffin. Whenever possible recommended regions according to the consensus criteria for diagnosing $\mathrm{AD}$ and DLB were used. ${ }^{522}$ Paraffin sections (2 $\mu \mathrm{m})$ were stained with haematoxylin and eosin and with Bielschowsky methods.

Immunocytochemistry was performed with monoclonal antibodies against a synthetic pep- tide corresponding to $138-152$ of the human prion protein (Gö138, Göttingen, Germany), $\beta$-amyloid ( $\beta \mathrm{A} 4$, Boehringer Mannheim, Germany), phosphorylated tau (AT8, Innogenetics, Ghent, Belgium), and a polyclonal antiserum against $\alpha$-synuclein (Q698, MPI Göttingen, Germany).

NEUROPATHOLOGICAL DIAGNOSTIC CRITERIA

Prion diseases

The definite diagnosis of prion disease is based on the detection of prion protein (PrP) deposits using PrP immunocytochemistry. ${ }^{23}$

Alzheimer's disease

Alzheimer's disease related pathology was classified using the CERAD pathological criteria based on semiquantitative analysis of neuritic plaques (Bielschowsky stain, aA4 immunostain $)^{24}$ as well as the Braak and Braak classification based on the distribution of neurofibrillary tangles and neuropil threads (Bielschowsky stain, AT8 immunostain). ${ }^{25}$

The 19 cases of AD were subclassified as CERAD C/Braak and Braak stage V-VI $(n=14)$ and CERAD B/Braak and Braak stage III-IV $(n=5)$.

Dementia with Lewy bodies

Distribution and frequency of Lewy bodies (LBs) were evaluated according to the consensus criteria for diagnosing DLB. ${ }^{5}$ The number of LBs were counted in the brain regions determined in the protocol ( $\alpha$-synuclein immunostain) and converted into scores from 0 (no LBs), 1 (1-4 LBs), and 2 (>5 LBs) for each area. Based on the total score, cases were divided into three subtypes: brainstem dominant, limbic, and neocortical.

The 12 cases of DLB examined here were subclassified as neocortical $(n=10)$ and limbic $(n=2)$ subtypes.

GENETIC ANALYSIS

A screening of mutations in the prion protein gene (PRNP) was performed in 20 patients with CJD using single strand conformation polymorphism (SSCP) analysis or direct DNA sequence analysis, as described previously. ${ }^{14}$ No mutations in PRNP were detected in the patients included in this study.

\section{Results}

PATIENTS

From June 1993 to June 1997 brain tissue from 413 suspected cases of CJD was examined in the German reference centre for spongiform encephalopathies. In 309 cases, sporadic CJD or genetic prion disease was confirmed; in 104 cases prion disease was ruled out. In these 104 cases, Alzheimer's disease was most often diagnosed (28 cases), followed by dementia with Lewy bodies (14 cases).

Nine patients with $\mathrm{AD}$ and two patients with DLB were excluded from the analysis because details of clinical examination were absent. Nineteen patients with $\mathrm{AD}$ and 12 patients with DLB were included in this study. Among these necropsy confirmed patients, 14 with $\mathrm{AD}$ and five with DLB were seen prospectively by a 
Table 1 Clinical signs and symptoms at onset of disease

\begin{tabular}{|c|c|c|c|}
\hline Initial signs/symptoms* & $\begin{array}{l}\text { CFD patients } \\
(\%) \\
(n=25)\end{array}$ & $\begin{array}{l}\text { AD patients } \\
(\%) \\
(n=19)\end{array}$ & $\begin{array}{l}\text { DLB patients } \\
(\%) \\
(n=12)\end{array}$ \\
\hline Dementia only & $7(28)$ & $12(63)$ & $5(42)$ \\
\hline Dementia+neurological signs/symptoms & $4(16) \dagger$ & $3(16) \dagger$ & $2(17) \dagger$ \\
\hline Dementia (total) & $11(44)$ & $15(79)$ & $7(58)$ \\
\hline Gait disturbances & $7(28)$ & $1(5)$ & - \\
\hline Visual disturbances & $7(27)$ & - & - \\
\hline Confusion & $4(16)$ & - & - \\
\hline Vertigo & $4(15)$ & $1(5)$ & - \\
\hline Aphasia & $2(8)$ & - & - \\
\hline Behavioural changes & $2(8)$ & - & - \\
\hline Dystonia & $1(4)$ & - & - \\
\hline Hallucinations & $1(4)$ & $1(5)$ & - \\
\hline Parkinsonism & $2(8)$ & - & $1(8)$ \\
\hline Limb paresis & $1(4)$ & - & - \\
\hline Myoclonus & - & $1(5)$ & - \\
\hline Epileptic seizures & - & $3(16)$ & - \\
\hline Delusion & - & - & $1(8)$ \\
\hline Aggressive behaviour & - & - & $1(8)$ \\
\hline No data & - & - & $3(25)$ \\
\hline
\end{tabular}

*Multiple mentioning possible.

$†$ Neurological signs in CJD patients were dystonia, gait disturbances, visual disturbances, and confusion; in $\mathrm{AD}$ patients they were myoclonus, epileptic seizures or gait disturbances; in DLB patients they were parkinsonism or visual hallucinations.

- Signs not noted.

member of the epidemiological CJD surveillance unit. The medical records were obtained from the remaining patients.

Twenty five patients with confirmed CJD served as a control group.

CLINICAL CHARACTERISTICS

In the CJD group, women and men were affected similarly (female:male=13:12), whereas women were overrepresented in the AD group (15:4) and less often diagnosed with DLB (4:8). The patients with CJD were younger (median 64 years, range $23-76$ years) than the patients with $\mathrm{AD}$ (76 years, 25-85

Table 2 Summary of clinical signs and symptoms during course of disease

\begin{tabular}{lccc}
\hline Sign/symptom & $\begin{array}{l}\text { CfD patients } \\
(\%) \\
(n=25)\end{array}$ & $\begin{array}{l}\text { AD patients } \\
(\%) \\
(n=19)\end{array}$ & $\begin{array}{l}\text { DLB patients } \\
(\%) \\
(n=12)\end{array}$ \\
\hline Dementia & $25(100)$ & $19(100)$ & $12(100)$ \\
Myoclonus & $22(88)$ & $11(58)$ & $9(75)$ \\
Extrapyramidal signs & $21(84)$ & $10(53)$ & $11(92)$ \\
$\quad$ Limb rigidity & $17(68)$ & $10(53)$ & $11(92)$ \\
$\quad$ Parkinsonism & $2(8)$ & $2(11)$ & $7(58)$ \\
$\quad$ Choreatic/athetoid/ballistic/dystonic signs & $10(40)$ & - & - \\
Pyramidal signs & $19(76)$ & $6(32)$ & $2(17)$ \\
Cerebellar signs & $23(92)$ & $7(37)$ & - \\
$\quad$ Gait or postural ataxia & $20(80)$ & $3(16)$ & \\
$\quad 15(60)$ & $5(26)$ & - \\
Visual disturbances & $12(44)$ & - & $1(8)$ \\
Akinetic mutism & $16(64)$ & $4(21)$ & $7(58)$ \\
Fluctuations & - & $1(5)$ & $7(58)$ \\
Visual hallucinations & $9(36)$ & $2(11)$ & $6(50)$ \\
Recurrent falls & $4(16)$ & $6(32)$ & $-\dagger$ \\
Neuroleptic hypersensitivity & $-\dagger$ & $-\dagger$ & $9(75)$ \\
Delusions & $3(12)$ & $5(26)$ &
\end{tabular}

${ }^{\star}$ Visual disturbances included deterioration of vision $(n=2)$, blurred vision $(n=3)$, visual field restriction $(n=4)$, disturbed perception of structures and colours $(n=3)$, and double vision $(n=3)$. †Neuroleptic medication was received by six AD patients, nine DLB patients, and one CJD patient without notice of hypersensitivity by treating physician.

- Signs not noted.

Table 3 Results of technical investigations

\begin{tabular}{llll}
\hline & $\begin{array}{l}\text { CfD patients } \\
(n=25)\end{array}$ & $\begin{array}{l}\text { AD patients } \\
(n=19)\end{array}$ & $\begin{array}{l}\text { DLB patients } \\
(n=12)\end{array}$ \\
\hline PSWCs in EEG & $56 \%(14 / 25)$ & $31 \%(5 / 16)$ & $8 \%(1 / 12)$ \\
Protein 14-3-3 in CSF & $87 \%(20 / 23)$ & $18 \%(2 / 11)$ & $\begin{array}{l}0 \%(0 / 5) \\
\text { Median NSE value in CSF (ng/ml) }\end{array}$ \\
$\begin{array}{ll}\text { (range: } 15-210) \\
\text { NSE raised in CSF }\end{array}$ & $\begin{array}{l}\text { (range: } 6-120) \\
\text { (range: } 6-22)\end{array}$ \\
\hline
\end{tabular}

PSWCs=periodic sharp wave complexes ${ }^{19}$; NSE is neuron specific enolase. years) and patients with DLB (72 years, 60-81years).

The median duration of illness varied from 4 months (range 2-24 months) in patients with CJD to 18.5 months (range $1-60$ months) in patients with DLB and 24 months (range 3-108 months) in patients with AD. A patient with $\mathrm{AD}$ was suspected of having CJD after 9 years of disease course when he developed rigidity and myoclonus.

REASONS FOR SUBMITTING BRAIN TISSUE FOR PRION DISEASE ANALYSIS

Patients with CfD ( $n=25)$

In 20 patients the primary clinical diagnosis was CJD, the remaining five patients were referred as patients with suspected CJD with other differential diagnoses.

Patients with $A D(n=19)$

Nine patients had rapidly progressive dementia with or without focal neurological signs and the EEG showed sharp wave complexes; therefore CJD was clinically suspected. "Probable" CJD was diagnosed in five of these patients with $\mathrm{AD}$ as sharp wave complexes fulfilled criteria for periodicity. ${ }^{19}$ In 10 further patients CJD was considered in the differential diagnosis as the disease course was very rapid.

Patients with DLB ( $n=12)$

One patient's clinical diagnosis by the notifying hospital was CJD, because of rapidly progressing illness with dementia, parkinsonian syndromes, and myoclonus, but without specific EEG findings. In the remaining patients CJD was suspected because of rapid progression of disease, and/or the development of myoclonus. In two of these patients, EEG showed sharp wave complexes, one of those fulfilled criteria for periodicity; therefore in this patient CJD was clinically "probable".

\section{CLINICAL SIGNS AND SYMPTOMS AT ONSET OF} DISEASE

The details are listed in table 1. Dementia was the first sign of disease in most patients with $\mathrm{AD}$ and those with DLB and in $44 \%$ of patients with CJD. Whereas patients with $\mathrm{AD}$ or with DLB often had dementia only, in many patients with CJD, dementia was accompanied by neurological signs or symptoms, or neurological signs preceded dementia.

CLINICAL SIGNS AND SYMPTOMS DURING THE COURSE OF DISEASE

All patients developed dementia. Myoclonus and extrapyramidal signs were especially common in patients with CJD and patients with DLB $(>80 \%$ and $>70 \%$ respectively) and in more than $50 \%$ of patients with $\mathrm{AD}$ (see table 2 for details). Extrapyramidal signs in patients with $\mathrm{AD}$ and with DLB were restricted to limb rigidity ( $>50 \%$ respectively) and parkinsonism (58\% in patients with DLB, $8 \%$ in CJD, and $11 \%$ in AD). Patients with CJD additionally showed hyperkinetic signs (40\%). Nearly all patients with CJD and $37 \%$ of patients with $\mathrm{AD}$ had cerebellar signs, not noted in DLB. Visual disturbances such as loss or deteriora- 
A

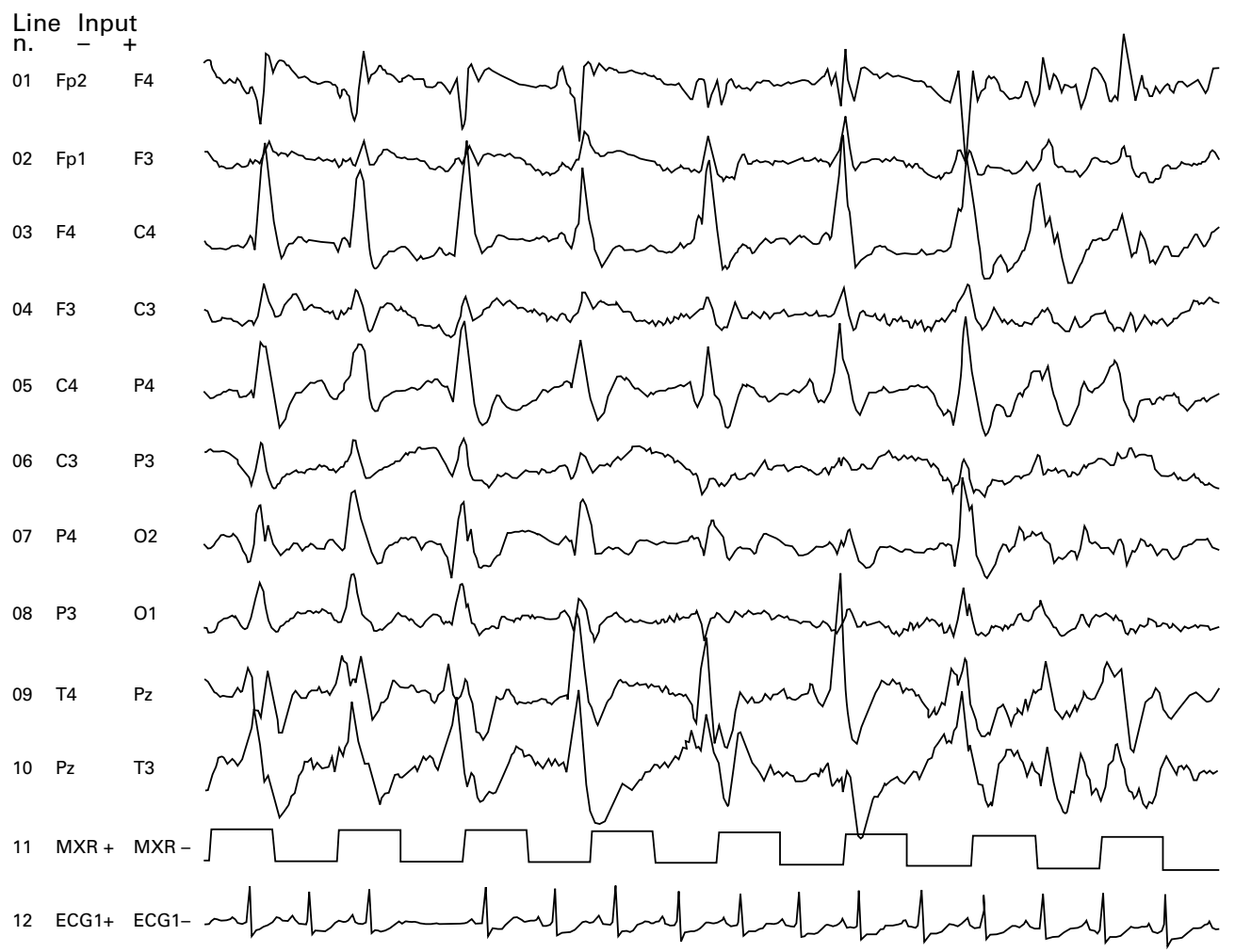

B

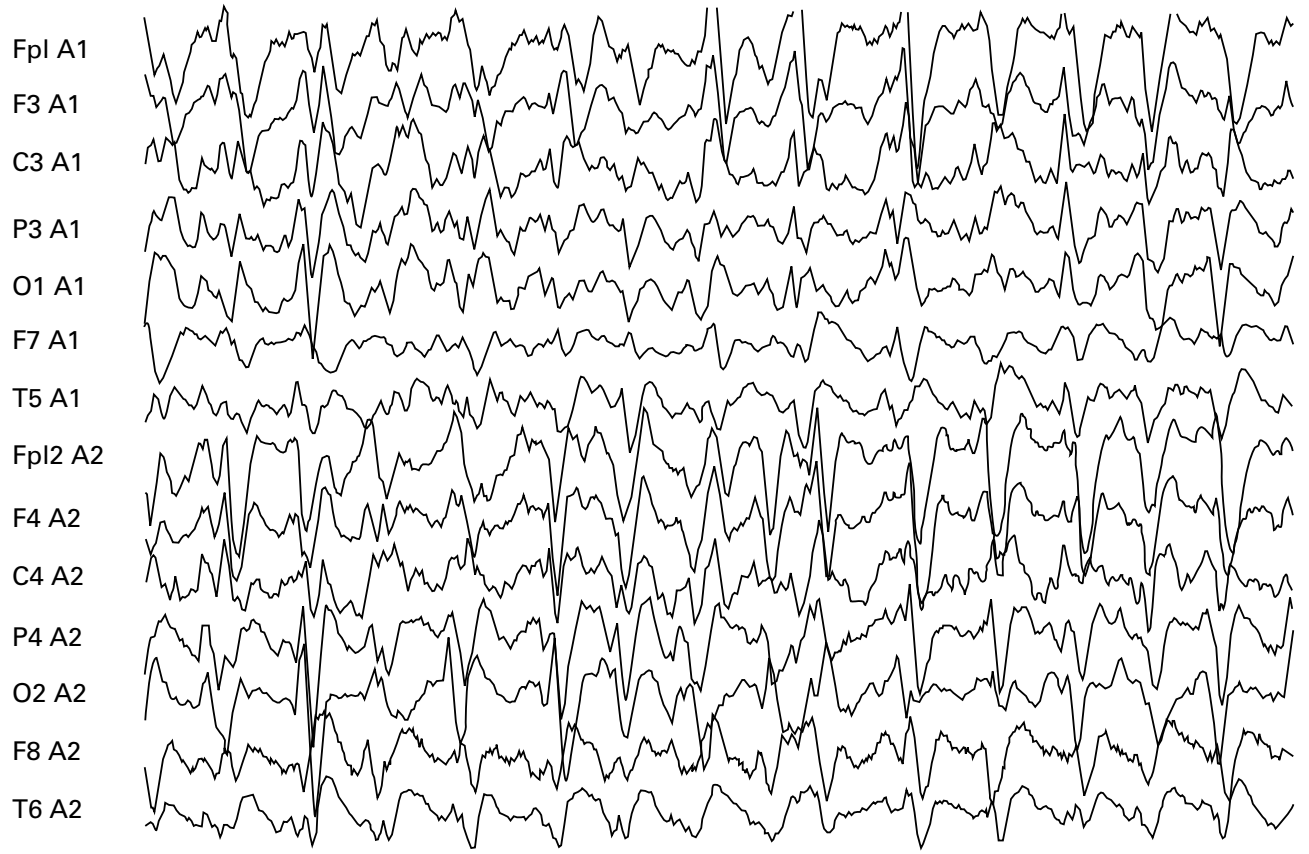

Figure 1 CFD typical periodic sharp wave complexes in EEGs from $(A)$ a histologically proved AD patient, aged 76 years after 4 months of disease (EEG curves by courtesy of Dr E Banzhaf). (B) A histologically proved patient with DLB, aged 77 years, after 36 months of disease (EEG curves by courtesy of Professor R Benecke).

tion of vision, visual field restriction, or disturbed perception of colours and structures were exclusively found in CJD (44\% of patients).

Signs typical of DLB such as fluctuations of cognitive impairment were found in $58 \%$ of patients with DLB, but only in one patient with $\mathrm{AD}$ and no patients with CJD. Visual halluci- nations were most common in DLB (58\%), but were also present in CJD (36\%) and $\mathrm{AD}$ (11\%). Referring physicians did not report neuroleptic hypersensitivity in any patient, including nine patients with DLB (75\%), six patients with $\mathrm{AD}(32 \%)$, and one patient with CJD (4\%) who had received neuroleptic medication. 


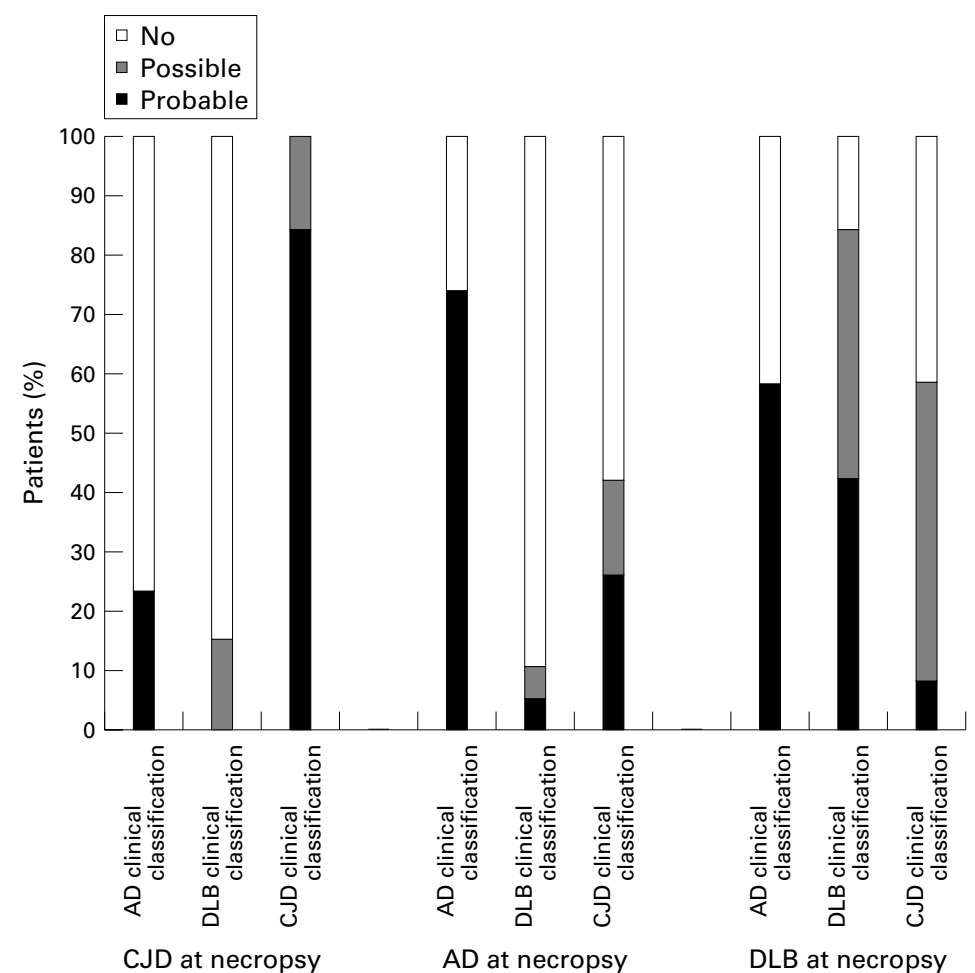

Figure 2 Clinical classification of necropsy proved patients. All patients were clinically classified as to whether $C F D, A D$, or DLB were clinically possible, probable, or not present.

RESULTS OF TECHNICAL INVESTIGATIONS

Periodic sharp wave complexes ${ }^{19}$ were present in $56 \%$ of patients with CJD, $31 \%$ of patients with $\mathrm{AD}$, and $8 \%$ of patients with DLB (fig $1 \mathrm{~A}$ and $B$, table 3 ).

Protein 14-3-3 $3^{16}$ was detectable in CSF in $87 \%$ of patients with CJD, $20 \%$ of patients with $\mathrm{AD}$ and in none of the five patients with DLB tested. The median of $\mathrm{NSE}^{16}$ was pathologically high in patients with CJD, but normal in patients with AD and those with DLB. According to previously established tests in our laboratory using an NSE value in CSF greater than $35 \mathrm{ng} / \mathrm{ml}$ as a cut off indicative for CJD, $73 \%$ of patients with CJD (16/22) had pathological NSE values, but only one of six patients with $\mathrm{AD}$ and none of the five patients with DLB tested did so. One patient with AD had CSF taken 4 days after an epileptic seizure. In this patient the protein 14-3-3 was detectable and NSE of $120 \mathrm{ng} / \mathrm{ml}$ was pathologically high. False positive results in CSF testing are known after epileptic seizures. ${ }^{16}$ The other patient with AD with detectable protein 14-3-3 in CSF had a normal NSE value.

\section{CLINICAL CLASSIFICATION OF PATIENTS}

Patients with definite CFD

"Probable" CJD was diagnosed in $84 \%$ of patients with CJD. In $16 \%$ (4/25) of patients with CJD technical investigations were not typical for CJD; therefore CJD was "possible". According to the diagnostic criteria for $\mathrm{AD}$ the diagnosis of AD was "probable" in $24 \%$ of cases. Sixteen per cent of patients with CJD fulfilled clinical criteria for "possible" DLB (dementia and visual hallucinations or parkinsonism).
Patients with definite $A D$

In $16 \%$ of patients with $\mathrm{AD}$ the diagnosis of "possible" CJD was made, in 26\% "probable" CJD was diagnosed clinically; $74 \%$ of patients with AD fulfilled clinical criteria of "probable" $\mathrm{AD}$; one patient with $\mathrm{AD}(5 \%)$ met the criteria for "probable" DLB (dementia, fluctuations, parkinsonism, and visual hallucinations); and one patient met the criteria for "possible" DLB (dementia and visual hallucinations). In another patient with $\mathrm{AD}$, dementia had preceded the development of parkinsonism by 9 years, so that in this case parkinsonism was not rated for the diagnosis of DLB. ${ }^{5}$

\section{Patients with definite DLB}

"Possible" CJD was diagnosed in $50 \%$ of patients with DLB, but only one patient with DLB had CJD typical PSWCs in EEG recordings and was therefore clinically "probable" CJD; $58 \%$ of patients with DLB met criteria for "probable" $\mathrm{AD} ; 84 \%$ of patients with DLB fulfilled clinical criteria for "possible" or "probable" DLB (42\% each, fig 2).

\section{Discussion}

Our series is the first to describe clinical findings on a large number of patients erroneously suspected of having Creutzfeldt-Jakob disease, who were histologically proved to have Alzheimer's disease or dementia with Lewy bodies. We are aware of only three comparable series $^{26-28}$ that report necropsy results of suspect patients with CJD who had other final diagnoses. Detailed clinical information was not given in these series. In all studies, $\mathrm{AD}$ was the most frequent alternative diagnosis; DLB was not mentioned, as it was only recently defined as a separate diagnostic entity.

As shown in clinicopathological studies, ${ }^{7} 2829$ clinical diagnosis in patients with dementia has become increasingly accurate, ranging from a specificity of $95 \%$ in $\mathrm{CJD}^{28}$ and $90 \%-97 \%$ in $\mathrm{DLB}^{7}$ to $79 \%{ }^{29}$ in $\mathrm{AD}$. Thus, patients with typical clinical presentation seem to be sufficiently covered by current diagnostic criteria. However, differential diagnosis is a major challenge in atypical cases, such as patients with rapidly progressive $\mathrm{AD}$ or DLB or patients with slowly progressive CJD.

In our study, CJD was suspected in patients with $\mathrm{AD}$ or DLB if the disease course was rapid or patients developed focal neurological signs, especially myoclonus, or if EEG was considered to point to CJD.

In most patients with $\mathrm{AD}$ or with DLB, dementia was present already at the onset of disease, corresponding to the literature. ${ }^{43} \mathrm{By}$ contrast, patients with CJD additionally had focal neurological signs such as gait or visual disturbances. During the course of disease dementia, myoclonus, and limb rigidity were the overlapping features of the three patient groups. Due to selection of "CJD-like" cases myoclonus was more common in DLB (75\%) and $\mathrm{AD}(58 \%)$ than usually reported $(19 \%$ in $\mathrm{DLB}^{19}$ and $10 \%$ in $\mathrm{AD}^{30}$ ). In accordance with the literature, ${ }^{9}{ }^{13}$ extrapyramidal signs were the cardinal features in patients with DLB. Parkinsonism was rarely found in patients with $\mathrm{AD}$ 
and those with CJD, but was present in $58 \%$ of patients with DLB. Although described also in $6 \%$ of patients with DLB in the literature,,$^{913}$ we found choreoathetoid or dystonic movements exclusively in patients with CJD. Clinical signs particularly common in CJD were ataxia and visual disturbances. A differentiation of visual disturbances from visual hallucinations was especially helpful. Although visual disturbances were found exclusively in CJD, visual hallucinations were present in all three dementias. As there are reports from non-CJD dementia syndromes which show predominantly visual impairments, this should be further investigated. ${ }^{31}$

Although the clinical course was more rapid and myoclonus was more common than generally, our patients with DLB showed the cardinal features of $\mathrm{DLB}^{5}$ (fig 3). Neuroleptic hypersensitivity, a complication in DLB, was not described in any of the patients by the treating physicians. Looking for the clinical details in our patients with DLB, nine of them received neuroleptic medication (median 2 months before death). In six of them, further clinical deterioration and death (median 1 month later) could be consistent with neuroleptic hypersensitivity as described in the literature. ${ }^{18}$ In three patients with DLB, no hypersensitivity to neuroleptic drugs was found, even with hindsight. Both factors, the lack of hypersensitivity in some patients and no clear correlation of clinical deterioration with administration of neuroleptic drugs, could have contributed to missing the clinical diagnosis of DLB.

Using the diagnostic criteria for PSWCs proposed by Steinhoff et al, ${ }^{19}{ }^{20}$ we found EEGs typical of CJD in $56 \%$ of patients with CJD, which is slightly less than previously reported. ${ }^{19}$ In five patients with $\mathrm{AD}$ and one patient with DLB, EEG was indistinguishable from typical CJD findings (fig $1 \mathrm{~A}$ and $\mathrm{B}$ ). In four additional patients with $\mathrm{AD}$ and two patients with DLB, EEG was considered by notifying hospitals to be compatible with CJD, but these EEGs did not correspond to the established criteria. The high frequency of false positive EEGs is most probably due to study design: demented patients are often referred due to "CJD-like"

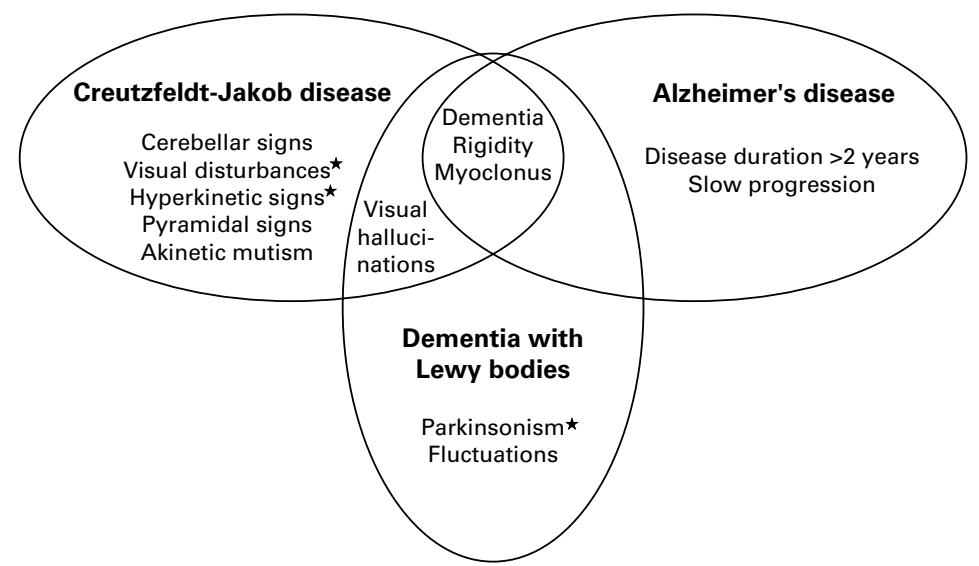

Figure 3 Clinical overlap between $C f D, A D$, and $D L B .{ }^{*}$ See materials and methods for definition.
EEG. In the literature there are reports on periodic sharp wave complexes in single cases of $\mathrm{AD}^{11}{ }^{12}$ and in two cases of DLB. ${ }^{13} 32$ "Pseudoperiodicity" in EEG is reported to be more often found in patients with DLB. ${ }^{33}$

Analysis of $\mathrm{CSF}^{16}$ yielded false positive results for 14-3-3 protein and NSE in one patient with $\mathrm{AD}$ and false positive 14-3-3 with normal NSE in another patient with AD. An explanation for the first patient could be an epileptic seizure 4 days before taking the CSF. In the five patients with DLB tested, 14-3-3 was negative and NSE was within the normal range. Negative findings for protein 14-3-3 and NSE in the CSF have also been found in five patients with DLB in another laboratory (Aksamit AJ, personal communication and Aksamit $e t a l^{34}$ ).

According to Parchi et $a l^{35}$ in sporadic CJD disease different subtypes exist. As described in detail by Zerr et al, ${ }^{36}$ the typical clinical phenotype with rapidly progressive dementia, myoclonus and typical EEG and CSF findings is present in about $70 \%$ of patients with CJD. In $10 \%$ of cases of CJD, disease duration is longer and patients often show extrapyramidal signs (MV2 subtype ${ }^{35}{ }^{37}$ ). In these patients EEG does not show CJD typical PSWCs and testing for protein 14-3-3 yields inconsistant results. ${ }^{36}$ The patients with MV2 and CJD could thus be missed or mistaken as a non-CJD neurodegenerative disorder, especially DLB. By contrast with $\mathrm{AD}$ or DLB, the patients with MV2 and CJD often exhibit ataxia as well as extrapyramidal features. Magnetic resonance imaging showing CJD typical findings in patients with $\mathrm{MV}^{38}$ could also help in the differential diagnosis. Due to lack of material no MR scans were described in this study.

Testing overlap in classification criteria (fig 2), we showed that "probable" CJD was misdiagnosed in six patients with the combination of limb rigidity, myoclonus, and false positive EEGs or CSF data. Classification of all patients according to AD criteria showed also that six patients with CJD and seven patients with DLB met criteria for "probable" AD. Comparable series on patients with DLB reported clinical criteria for "probable" AD in $15 \%$ and for "possible" $\mathrm{AD}$ in $50 \%$ of cases. ${ }^{7}$ In our study, DLB criteria specifically identified $84 \%$ of patients with DLB and falsely classified 16\% of patients with CJD and $11 \%$ of patients with $\mathrm{AD}$ as having DLB.

Although our patients with DLB showed the major clinical signs of DLB (table 2), this disease was not mentioned as a clinical diagnosis in any of our patients. This accords with general findings that DLB escapes diagnosis in up to $66 \%$ of cases during a lifetime, ${ }^{8}$ probably because it is still quite unknown to the clinicians and specific technical examinations for DLB are lacking.

In summary, in patients with rapidly progressive dementia and focal neurological signs, CJD should be the primary diagnosis, especially if EEG shows periodic sharp wave complexes or if the 14-3-3 protein is detectable in CSF (fig 4). Ataxia, visual disturbances, and hyperkinetic limb movements are strong 


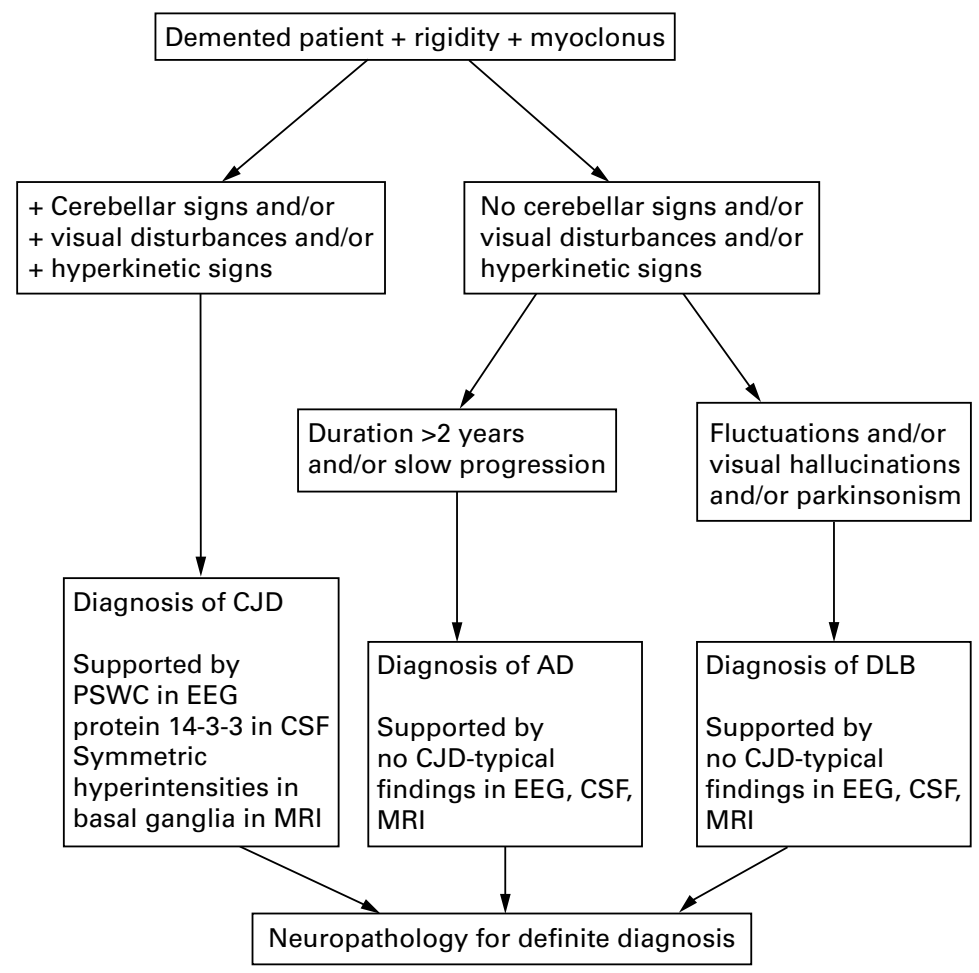

Figure 4 Diagnostic pattern in the differential diagnosis of patients with the triad dementia, myoclonus, and rigidity.

hints for CJD. In a patient with the triad dementia, myoclonus, and rigidity with or without EEG changes, the history should be thoroughly reinvestigated to exclude the possibility that the current condition is the end state of a dementia disorder with a longer duration. In the second case, $\mathrm{AD}$ should be considered. A suspicion of DLB should be raised, if an akinetic rigid parkinsonism or fluctuations in cognition are present.

This study was supported by a grant from the Bundesministerium fur Gesundheit, Bonn, Germany, to HAK and to SP (BMG referred suspect patients to the German reference centre for and clinical data. We are especially obliged to Professor R and clinical data. We are especially obliged to Professor R
Benecke, University of Rostock, Germany and to Dr E Banzhaf, Benecke, University of Rostock, Germany and to Dr E Banzhaf,
Klinikum Meiningen GmbH, Germany, for kindly providing Klinikum Meiningen GmbH, Germany, for kindly providing EEG curves. We thank Dr Otto Windl, Department of
Neuropathology, University of Göttingen for analysis of the Neuropathology, University of Göttingen for analysis of the
prion protein (PrP) gene (PrNP). We express our thanks to Drs prion protein (PrP) gene (PrNP). We express our thanks to Drs
Sabine Räcker, Stefan Grosche, Annemarie Szudra, Maria Sabine Räcker, Stefan Grosche, Annemarie Szudra, Maria Seipelt, Waldemar Murach, Kati Weidehaas, Anke Vogt, and
Stefan Kropp, who worked as visiting physicians in the CJD Stefan Kropp, who worked as visiting physicians in the CJD surveillance unit. We are obliged to Monika Bodemer and Barbara Ciesielczyk, for CSF analysis, Maja Schneider-Dominco, and Drs Markus Otto and Jens Wiltfang for their support.

1 Poser S, Zerr I, Schulz-Schaeffer W, et al. Die CreutzfeldtJakob-Krankheit. Eine Sphinx der heutigen Neurobiologie. Jakob-Krankheit. Eine Sphinx der heutigen
Dtsch Med Wochenschr 1997;122:1099-105.

2 Gómez-Tortosa E, Ingraham AO, Irizarry $\mathrm{MC}$, et al. Dementia with Lewy bodies. F Am Geriatr Soc 1998;46: 1449-58.

3 Häfner H. Epidemiology of Alzheimer's disease. In: Maurer $\mathrm{K}$, et al, eds. Epidemiology, neuropathology, neurochemistry and clinics. Wien: Springer, 1990:23-39.

4 McKhann G, Drachman D, Folstein M, et al. Clinical diag nosis of Alzheimer's disease: report of the NINCDSADRDA work group under the auspices of the Department of Health and Human Services task force of Alzheimer's disease. Neurology 1984;34:939-944.

5 McKeith IG, Galasko D, Kosaka K, et al. Consensus guidelines for the clinical and pathological diagnosis of dementia with Lewy bodies (DLB): report of the consortium on DLB international workshop. Neurology 1996;47:1113-24.

6 Heyman A, Fillenbaum GG, Gearing M, et al. Comparison Heyman A, Fillenbaum GG, Gearing M, et al. Comparison
of Lewy body variant of Alzheimer's disease with pure of Lewy body variant of Alzheimer's disease with

7 McKeith IG, Fairbairn AF, Bothwell RA, et al. An evaluation of the predictive validity and inter-rater reliabil- ity of the clinical diagnostic criteria for senile dementia of Lewy body type. Neurology 1994;44:872-7.

8 Litvan MD, MacIntyre A, Goetz CG, et al. Accuracy of the clinical diagnosis of Lewy body disease, Parkinson disease and dementia with Lewy bodies. Arch Neurol 1998;55:96978

9 Louis ED, Klatka LA, Liu Y, et al. Comparison of extrapyramidal features in 31 pathologically confirmed cases of diffuse Lewy body disease and 34 pathologically confirmed cases of Parkinson's disease. Neurology 1997;48:376-80.

10 Faden AI, Townsend J. Myoclonus in Alzheimer disease. A confusing sign. Arch Neurol 1976;33:278-80.

11 Katz PR, Chutkow JG. Dementia, myoclonus and EEG findings typical of Creutzfeldt-Jakob disease in a patient with Alzheimer's disease. N Y S F Med 1986;86:157-8.

12 Watson CP. Clinical similarity of Alzheimer and Creutzfeldt-Jakob disease. Ann Neurol 1979;6:368-9.

13 Burkhardt CR, Filley CM, Kleinschmidt-DeMasters BK, et al. Diffuse Lewy body disease and progressive dementia. Neurology 1988;38:1520-8.

14 Windl O, Giese A, Schulz-Schaeffer W, et al. Molecular genetics of human prion diseases in Germany. Hum Genet 1999;105:244-52.

15 Masters CL, Harris JO, Gajdusek DC, et al. CreutzfeldtJakob disease: patterns of worldwide occurrence and the significance of familial and sporadic clustering. Ann Neurol 1979;5:177-88.

16 Zerr I, Bodemer M, Gefeller O, et al. Detection of 14-3-3 protein in the cerebrospinal fluid supports the diagnosis of Creutzfeldt-Jakob disease. Ann Neurol 1998;43:32-40.

17 Otto A, Zerr I, Lantsch M, et al. Akinetic mutism as a classification criterion for the diagnosis of Creutzfeldt-Jakob disease. 7 Neurol Neurosurg Psychiatry 1998;64:524-8.

18 McKeith IG, Fairbairn AF, Perry RH, et al. Neuroleptic hypersensitivity in patients with senile dementia of Lewy hypersensitivity in patients with
body type. $B M F$ 1992;305:673-8.

19 Steinhoff BJ, Räcker S, Herrendorf G, et al. Accuracy and reliability of periodic sharp wave complexes in CreutzfeldtJakob disease. Arch Neurol 1996;53:162-6.

20 World Health Organization. Human transmissible spongiform encephalopathies. Weekly Epidemiological Record 1998; 73:361-5.

21 Brown P, Gajdusek DC. A simple and effective method for inactivating virus infectivity in formalin-fixed tissue samples from patients with Creutzfeldt-Jakob disease. Neurology 1990;40:887-90.

22 Hyman BT, Trojanowski JQ. Editorial recommendations for the postmortem diagnosis of Alzheimer's disease from the National Institute on Aging and the Reagan Institute Working Group on the diagnostic criteria for the neuropathological assessment of Alzheimer's disease. $7 \mathrm{Neu}$ ropathol Exp Neurol 1997;56:1095-7.

23 Kretzschmar HA, Ironside JW, DeArmond SJ, et al. Diagnostic criteria for sporadic Creutzfeldt-Jakob disease. Diagnostic criteria for sporadic

24 Mirra SS, Heyman AA, McKeel D, et al. The Consortium to Establish a Registry for Alzheimer's disease (CERAD). Part II. Standardization of the neuropathologic assessment of Alzheimer's disease. Neurology 1991;41:479-86.

25 Braak H, Braak E. Neuropathologic staging of Alzheimerrelated changes. Acta Neuropathol 1991;82:239-59.

26 Brown P, Gibbs CJJr, Rodgers-Johnson P, et al. Human spongiform encephalopathy: the National Institutes of Health series of 300 cases of experimentally transmitted disease. Ann Neurol 1994;35:513-29.

27 Will RG, Matthews WB. A retrospective study of Creutzfeldt-Jakob disease in England and Wales 1970-79. I: clinical features. $\mathcal{F}$ Neurol Neurosurg Psychiatry 1984;47: 134-40.

28 Poser S, Mollenhauer B, Krau $\beta$ A, et al. How to improve the clinical diagnosis of Creutzfeldt-Jakob disease. Brain 1999; 122:2345-51.

29 Lopez OL, Litvan I, Catt KE, et al. Accuracy of four clinical diagnostic criteria for the diagnosis of neurodegenerative dementias. Neurology 1999;53:1292-9.

30 Hauser WA, Morris ML, Heston LL, et al. Seizures and myoclonus in Alzheimer's disease. Neurology 1986;36: 1226-30.

31 Pantel J, Schröder J. Posterior cortical atrophy: ein neues Demenzsyndrom oder Sonderform des Morbus Alzheimer? Fortschr Neurol Psychiatr 2000;64:492-508.

32 Yamamoto T, Imai T. A case of diffuse Lewy body disease and Alzheimer's disease with periodic synchronous discharges. F Neuropathol Exp Neurol 1988;47:536-48.

33 Crystal HA, Dickson DW, Lizardi JE, et al. Antemortem diagnosis of diffuse Lewy body disease. Neurology 1990;40: 1523-8.

34 Aksamit AJ, Homburger HA, Preissner CM. CreutzfeldtJakob disease: correlation with spinal fluid NSE and 14-3-3 proteins. F Neurol 1999;246(suppl 1):I-33

35 Parchi P, Giese A, Capellari S, et al. Classification of sporadic Creutzfeldt-Jakob disease based on molecular and phenotypic analysis of 300 subjects. Ann Neurol 1999;46: 224-33.

36 Zerr I, Schulz-Schaeffer WJ, Giese A, et al. A clinical diagnosis in Creutzfeldt-Jakob disease: identification of unkommon variants? Ann Neurol 2000;48:323-9.

37 Samman I, Schulz-Schaeffer WJ, Wohrle JC, et al. Clinical range and MRI in Creutzfeldt-Jakob disease with heterozygosity at codon 129 and prion protein type 2 . $\mathcal{F}$ Neurol Neurosurg Psychiatry 1999;67:678-81.

38 Schröter A, Zerr I, Henkel K, et al. Magnetic resonance imaging (MRI) in the clinical diagnosis of CreutzfeldtJakob disease. Arch Neurol 2000;57:1751-7. 